Published in final edited form as:

Curr Dir Psychol Sci. 2008 June 28; 17(3): 213-218. doi:10.1111/j.1467-8721.2008.00577.x.

\title{
Learning to Move
}

\author{
Karen E. Adolph
}

Department of Psychology, New York University, 4 Washington Place, Room 410, New York, NY 10003

\begin{abstract}
Locomotion-moving the body from place to place-is one of infants' greatest achievements. In addition to conquering gravity, infants must cope with variable and novel constraints on balance and propulsion. At the same time that they are learning to move, changes in infants' bodies, skills, and environments change the biomechanical constraints on movement. Recent work highlights both flexibility and specificity in infants' responses to novel and variable situations, demonstrating that infants are learning to learn as they master locomotion. Within sitting, crawling, cruising, and walking postures, experienced infants adapt their locomotor responses to the current biomechanical constraints on movement. However, what infants have learned about coping with variability and novelty in earlier-developing postures does not transfer to later-developing postures.
\end{abstract}

\section{Keywords}

locomotion; perception-action; crawling; walking; learning to learn

Locomotion is one of infants' greatest accomplishments. At birth, infants are slaves to gravity. By the end of their first year, they have mastered an enormous array of locomotor movements: rolling, bum shuffling, belly crawling, hands-and-knees crawling, cruising sideways along furniture, supported stepping, independent walking, and so on. Since the early 1900s, researchers have catalogued infants' many forms of locomotion, assigning ages and stages to the progression from immobility to independent walking. Indeed, the legacy of the early pioneers in motor development is the notion of an orderly march of locomotor stages, unfolding as a byproduct of neural-muscular maturation (e.g., Gesell, 1946;

McGraw, 1945). An unfortunate consequence of this maturational legacy is that outside the small coterie of researchers who study motor development, there is little recognition of the learning involved in moving the body from place to place.

\section{CHANGING CONSTRAINTS ON MOBILITY}

Overcoming gravity requires sufficient strength to support the body's mass, balance to maintain the body's position, and coordination to move the relevant body parts. But, gravity is not the only challenge. Rapid and dramatic changes in infants' bodies, skills, and environments can pose additional difficulties, and greatly expand or curtail possibilities for locomotion. Even subtle changes such as wearing a diaper or crawling over plush carpet can alter the biomechanical constraints on balance and propulsion. As a consequence, infants must continually update their assessment of their abilities relative to the environment so as to take changing possibilities for action into account.

Address correspondence to Karen E. Adolph, Department of Psychology, New York University, 4 Washington Place, Room 410, New York, NY 10003; e-mail: karen.adolph@nyu.edu.. 
Over the first 2 years of life, body weight nearly quadruples, height doubles, and head circumference increases by a third. Growth occurs in fits and starts, such that infants may grow 1 to 2 centimeters taller overnight (e.g., Lampl, Veldhuis, \& Johnson, 1992). Changes in motor skills are equally dramatic (for review, see Adolph \& Berger, 2006; Bertenthal \& Clifton, 1998). Precarious "tripod" sitting is replaced by stable, hands-free sitting. Crawling with the belly dragging along the floor gives way to crawling on hands and knees. Pulling to a stand is followed quickly by cruising sideways along furniture. Free standing soon leads to walking. Initial improvements in each posture are extremely rapid (Adolph, Vereijken, \& Denny, 1998; Adolph, Vereijken, \& Shrout, 2003; Bril \& Ledebt, 1998). After a few months of experience, crawling and walking infants can race across the floor.

Changing body dimensions and skills introduce infants to novel features of the environment. New surfaces in new configurations present an expanding array of obstacles. The ground may be multileveled, sloping, slippery, or deformable. The path may be obstructed by people or furniture or terminate in a drop-off or gap between supports.

\section{LEARNING TO LEARN TO LOCOMOTE}

Given the sea of developmental changes that accompany new ways of moving, a repertoire of fixed locomotor forms unfolding in orderly stages, as suggested by the early pioneers in motor development, would be maladaptive. Instead, locomotion must be improvisatory and flexible (Gibson \& Schmuckler, 1989; Thelen, 1995). Variability and novelty are the rule, not the exception. I have proposed that adapting locomotion to the current constraints on action involves a continual process of online problem solving (Adolph, 2002, 2005; Adolph \& Berger, 2006), a process akin to Harlow's (1949) notion of "learning to learn." Harlow coined the expression to distinguish the means for finding solutions to novel problems from simple associative learning and stimulus generalization. Learning to learn is limited only by the boundaries of the particular problem space- the set of task-relevant parameters and their values that define a class of problems.

I have co-opted Harlow's expression to refer to infants' acquisition of means for detecting novel and variable constraints on locomotion and for discovering new solutions to respond adaptively. Exploration plays a critical role in learning to learn. Perceptual information generated by infants' present movements can be used to guide their subsequent movements (von Hofsten, 2004) - visual exploration as infants notice an obstacle or target, proprioceptive exploration as they step and sway during their approach, haptic exploration as they probe the surface or space with a limb, means-ends exploration as they test various alternatives, and so on. In learning to learn, rather than learning cue-consequence associations (slopes are paired with falling), facts (slopes are dangerous), or particular solutions for familiar problems (avoid walking down slopes), infants acquire the ability to generate relevant information about novel locomotor problems and their potential solutions (e.g., on their first encounter with a slope, they perceive whether balance will be compromised and figure out an alternative, more stable position for descent).

As in Harlow's theory, learning to learn in the realm of motor skills is limited by the boundaries of the problem space. Because sitting, crawling, cruising, and walking are defined by different critical parameters, each posture in development constitutes a distinct problem space. Each involves different muscle groups for balance and propulsion, regions of permissible postural sway, vantage points for viewing the environment, sources of perceptual information, correlations between visual, vestibular, and proprioceptive inputs, and so on. As infants gain experience with a new posture, they must identify the critical parameters for the particular problem space, and acquire the exploratory procedures to calibrate the settings of those parameters under changing conditions. According to this view, 
the development of locomotion is not a series of functionally related stages, as the early pioneers had proposed, because learning to learn in an earlier developing posture does not transfer to a later-developing posture. Each problem space has its own set of informationgenerating behaviors and its own learning curve.

However, the benefit of the staggered emergence of sitting, crawling, cruising, and walking over several months of development is that the opportunities for learning about each posture are immense. For example, according to a recent estimate (Adolph, Badaly, Garciaguirre, \& Sotsky, 2008), each hour, 14-month-olds take more than 2,000 walking steps, travel an accumulated distance of 7 football fields, and incur 15 (usually inconsequential) falls.

\section{EVIDENCE FOR LEARNING TO LEARN: FLEXIBILITY AND SPECIFICITY}

The strongest evidence for learning to learn in the development of balance and locomotion comes from studies of infants facing variable and novel challenges (for review, see Adolph, 1997, 2002, 2005; Adolph \& Berger, 2006). Infants descending slopes (Fig. 1A), spanning gaps (Fig. 1B-E), and crossing bridges (Fig. 1F-H) were especially useful paradigms for several reasons. First, the tasks were novel for infants. Thus, adaptive responses could not be based on prior experiences in similar situations. 7 Second, environmental features (degree of slant, gap size, and bridge width) varied continuously, allowing precise assessment of whether infants responded adaptively to changing biomechanical constraints. Third, infants' abilities in these tasks were affected by changes in body dimensions, changes in skill levels, and transitions from earlier- to later-developing postures, allowing assessment of flexible adaptation within postures and specificity between postures. Fourth, possibilities for balance and locomotion were specified by multiple sources of perceptual information. Thus, exploratory behaviors could be linked to adaptive responding. Finally, falling down a slope or into a precipice was an aversive consequence, motivating infants to respond adaptively.

We observed infants over dozens of trials while varying increment size from trial to trial. We compared infants' attempt rates on safe and risky increments to their success rates at those same increments. For example, if an infant's success at walking down slopes decreased from $100 \%$ to $0 \%$ between $20^{\circ}$ and $24^{\circ}$, then slopes shallower than $20^{\circ}$ would be safe, slopes steeper than $24^{\circ}$ would be risky, and slopes between the two increments would be intermediate in risk. We asked whether infants would respond adaptively by attempting safe increments within their abilities (the steepest slope, widest gap, or narrowest bridge the infant could navigate in a given posture) and by avoiding risky increments beyond their abilities.

The data from these paradigms indicate that flexible and adaptive solutions require learning. When infants first acquired a new posture, they appeared oblivious to the limits of their abilities relative to environmental features. For example, in their first weeks of crawling and walking, infants plunged straight down impossibly steep slopes (Adolph, 1997). Over weeks of locomotor experience, exploratory behaviors became more discerning and responses became more adaptive: Infants attempted safe slopes and refused to crawl or walk down risky ones. Across various developmental research designs (longitudinal observations from infants' first week of crawling until several weeks after they began walking, cross-sectional samples from 8 to 18 months of age, and an age-matched design in which all infants were 12 months old but half were experienced crawlers and half were novice walkers), locomotor experience was a better predictor of adaptive responding than was age.

Several lines of evidence suggest that infants were learning to learn rather than learning particular solutions. The signature characteristic of learning to learn is responding adaptively to novel problems within the boundaries of a given problem space; that is, infants should not require experience with a particular locomotor problem such as slopes to respond 
adaptively; only experience maintaining balance in a particular posture such as crawling is needed. Indeed, experienced sitters, crawlers, cruisers, and walkers responded adaptively when navigating slopes, gaps, and bridges for the first time in their experienced posture, indicating that they could cope with novel variations in the environment. Similarly, experienced infants updated their assessment of risk based on naturally occurring and experimentally induced changes in their bodies and skills. For example, wearing leadweighted shoulder packs reduced infants' ability to walk down slopes by 4 to $5^{\circ}$. Experienced walkers adapted to the novel constraints of their altered abilities by modifying step length, velocity, and posture to accommodate the loads (Garciaguirre, Adolph, \& Shrout, 2007). More impressively, they correctly treated slopes that were safe while wearing feather-weighted shoulder packs as risky when they were loaded with lead-weighted packs (Adolph \& Avolio, 2000). For example, experienced walkers might attempt to walk down a $20^{\circ}$ slope that was safe in the feather-weighted shoulder packs but attempt only a $16^{\circ}$ slope while wearing the lead-weighted shoulder packs.

A second characteristic of learning to learn is a flexible variety of solutions compiled on the fly rather than a fixed solution drawn from an existing repertoire. Experienced crawlers and walkers figured out new ways of descending slopes, and they exhibited multiple solutions within sessions such as sliding down in sitting, backing, and head-first positions (Fig. 2). Occasionally, infants' inventive solutions outwitted the experimenters. Experienced walkers went straight across wide bridges but only crossed narrow bridges when a sturdy, wooden handrail was available to augment their balance. As expected, infants were less likely to cross narrow bridges if the handrail was made of wobbly rubber so that it dipped to the floor when infants leaned their full weight on it (Berger, Adolph, \& Lobo, 2005). However, to our surprise, a wobbly handrail was better than no handrail at all. Most infants devised new locomotor strategies to safely cross narrow bridges with the wobbly handrail, such as leaning backward as if mountain climbing or wind surfing (Fig. 2).

A third characteristic of learning to learn is failure to transfer outside the boundaries of the problem space. For motor development, this would mean specificity between experienced and novice postures. The results are most striking in within-subject comparisons, in which infants were tested in the same session in both postures. New walkers avoided a risky $36^{\circ}$ slope when tested in their experienced crawling posture but attempted to walk down the same slope when tested moments later in their novice, unfamiliar upright posture (Adolph, 1997). Similarly, 9-month-olds avoided risky gaps in an experienced sitting posture but fell repeatedly into the precipice when tested in a novice crawling posture (Adolph, 2000). Cruising infants gauged precisely how far they could stretch their arms over an adjustable gap in a handrail but stepped blithely into 90-centimeter gaps in the floor, as if they did not realize that walking requires a floor to support the body (Adolph, 2005). We found no evidence of within-session transfer from earlier-developing postures to later-developing ones. In fact, learning took just as long the second (and third, etc.) time around.

\section{LESSONS FROM INFANT LOCOMOTION}

The notion of learning to learn provides a framework for understanding how ongoing actions are adapted to cope with variability and novelty. In addition to highlighting the importance of behavioral flexibility in the development of balance and locomotion, findings also emphasize the limits on learning to learn. Discontinuities between sitting, crawling, cruising, and walking postures illustrate how solutions at one point in development may be specific to that developmental niche. For example, although cruising typically appears before walking and shares a similar upright appearance, the earlier-developing posture may be functionally distinct from the later-developing one in terms of infants' ability to adapt movements to 
novel situations. Temporal contiguity and structural similarity in development do not necessarily entail functional relatedness.

The findings also lend support to two, broad generalizations about learning and development. First, learning is always nested in the context of larger developmental changes. Changes in bodies, skills, and environments are especially dramatic during infancy, but we never cease developing. A second, related point is that we are always learning to learn to move. Development is an exaggerated version of the temporary 11 changes that result from the flux of everyday activity. Environments and bodies are always variable. A gravel road or high-heeled shoes change the biomechanical constraints on balance and locomotion. Clearly, the ability to solve novel problems is effective for a broader range of situations than learning particular solutions for familiar problems is. Fixed facts, cueconsequence associations, and stimulus generalizations are insufficient to promote adaptive responding to the variable and novel situations characteristic of everyday life.

An important area for future research is to determine the limits on learning to learn. Relatedly, what makes a skill a distinct postural control system? A promising avenue of investigation is skill acquisition throughout the lifespan. After infancy, skills such as bicycling and swimming are likely candidates for distinct postural control systems because each involves very different parameters (body parts for balance and propulsion, sources of perceptual information, etc.) from those acquired for sitting, crawling, cruising, and walking postures. Skills such as twirling a hula-hoop or gliding on ice skates are wonderful examples of how children can expand an existing problem space such as walking. Changes in skill due to aging require a different sort of flexibility and growth with an existing problem space.

\section{Acknowledgments}

This work was supported by National Institute of Child Health and Human Development Grants HD-33486 and HD-42697.

\section{Recommended Reading}

Adolph KE. A detailed account of flexibility and specificity in infant locomotion over slopes, including a review of the literature on the development of infant locomotion. 1997 See References.

Adolph KE, Berger SE. An in-depth examination of central issues in developmental psychology using examples from motor development. 2006 See References.

Campos JJ, Anderson DI, Barbu-Roth MA, Hubbard EM, Hertenstein MJ, Witherington DC. Travel broadens the mind. Infancy. 2000; 1:149-219. An account of how the development of balance and locomotion facilitates improvements in other developmental domains.

Gibson, EJ.; Pick, AD. An ecological approach to perceptual learning and development. Oxford University Press; New York: 2000. A clearly written, highly accessible introduction to the perception-action approach to development.

von Hofsten C. A short review with examples of how perception guides goal-directed motor action. 2004 See References.

\section{REFERENCES}

Adolph KE. Learning in the development of infant locomotion. Monographs of the Society for Research in Child Development. 1997; 62(3) Serial No. 251.

Adolph KE. Specificity of learning: Why infants fall over a veritable cliff. Psychological Science. 2000; 11:290-295. [PubMed: 11273387]

Adolph, KE. Learning to keep balance. In: Kail, R., editor. Advances in child development and behavior. Vol. 30. Elsevier Science; Amsterdam: 2002. p. 1-40. 
Adolph, KE. In: Lockman, J.; Reiser, J., editors. Learning to learn in the development of action; Action as an organizer of learning and development: The 32nd Minnesota Symposium on Child Development; Hillsdale, NJ: Erlbaum. 2005; p. 91-122.

Adolph KE, Avolio AM. Walking infants adapt locomotion to changing body dimensions. Journal of Experimental Psychology: Human Perception and Performance. 2000; 26:1148-1166. [PubMed: 10884014]

Adolph, KE.; Berger, SE. Motor development. In: Kuhn, D.; Siegler, RS., editors. Handbook of child psychology: Vol. 2. Cognition, perception, and language. 6th ed.. John Wiley \& Sons; New York: 2006. p. 161-213.

Adolph, KE.; Badaly, D.; Garciaguirre, JS.; Sotsky, RB. 15,000 steps: Infants' walking experience. 2008. Manuscript in preparation

Adolph KE, Vereijken B, Denny MA. Learning to crawl. Child Development. 1998; 69:1299-1312. [PubMed: 9839417]

Adolph KE, Vereijken B, Shrout PE. What changes in infant walking and why. Child Development. 2003; 74:474-497.

Berger SE, Adolph KE, Lobo SA. Out of the toolbox: Toddlers differentiate wobbly and wooden handrails. Child Development. 2005; 76:1294-1307. [PubMed: 16274441]

Bertenthal, BI.; Clifton, RK. Perception and action. In: Kuhn, D.; Siegler, RS., editors. Handbook of child psychology: Vol. 2. Cognition, perception, and language. 5th ed.. John Wiley \& Sons; New York: 1998. p. 51-102.

Bril B, Ledebt A. Head coordination as a means to assist sensory integration in learning to walk. Neuroscience and Biobehavioral Reviews. 1998; 22:555-563. [PubMed: 9595569]

Garciaguirre JS, Adolph KE, Shrout PE. Baby carriage: Infants walking with loads. Child Development. 2007; 78:664-680. [PubMed: 17381796]

Gesell, A. The ontogenesis of infant behavior. In: Carmichael, L., editor. Manual of child psychology. John Wiley; New York: 1946. p. 295-331.

Gibson EJ, Schmuckler MA. Going somewhere: An ecological and experimental approach to development of mobility. Ecological Psychology. 1989; 1:3-25.

Harlow HF. The formation of learning sets. Psychological Review. 1949; 56:51-65. [PubMed: 18124807]

Lampl M, Veldhuis JD, Johnson ML. Saltation and stasis: A model of human growth. Science. 1992; 258:801-803. [PubMed: 1439787]

McGraw, M. The neuromuscular maturation of the human infant. Columbia University Press; New York: 1945.

Thelen, E. The improvising infant: Learning about learning to move. In: Merrens, MR.; Brannigan, GG., editors. The developmental psychologists: Research adventures across the lifespan. McGrawHill; New York: 1995. p. 21-36.

von Hofsten C. An action perspective on motor development. Trends in Cognitive Sciences. 2004; 8:266-272. [PubMed: 15165552] 


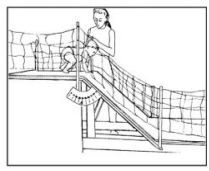

c.

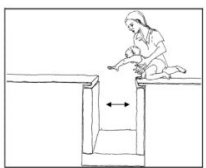

E.

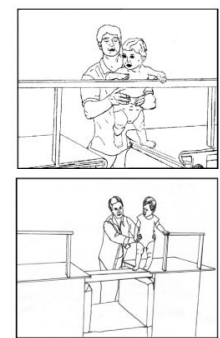

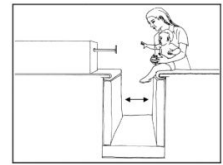

D.

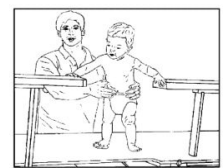

F.

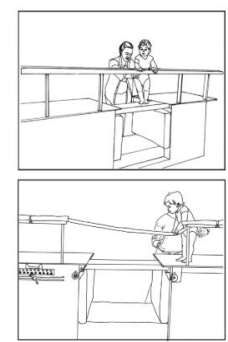

Fig. 1.

Paradigms for presenting infants with variable and novel challenges to balance and locomotion: (A) descending a walkway with adjustable slope; (B) spanning an adjustable gap in a sitting posture and (C) a crawling posture; (D) cruising over a solid floor with an adjustable gap in the handrail used for support and (E) over an adjustable gap in the floor with a solid handrail used for support; and $(F)$ walking over bridges of adjustable width with a sturdy handrail available to augment balance, $(\mathrm{G})$ without a handrail, and $(\mathrm{H})$ with a wobbly handrail. 


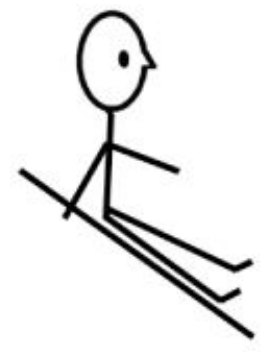

sit

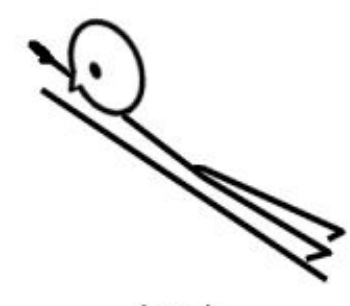

back

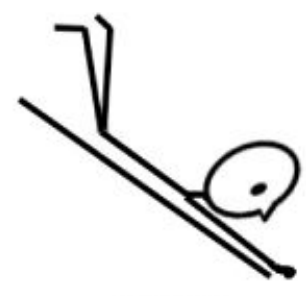

prone

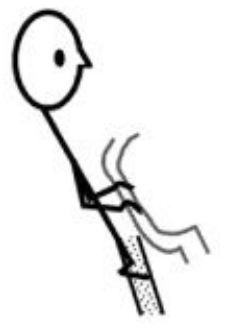

windsurfing

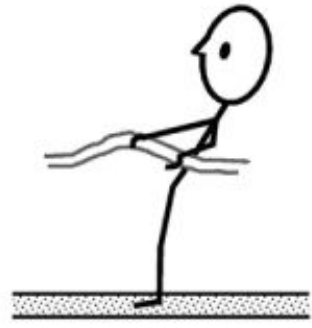

mt. climbing

Fig. 2.

Some of the solutions infants used to descend steep slopes and to cross narrow bridges while holding onto a wobbly handrail for support. 